\title{
Synchronous giant gastric gastrointestinal stromal tumor and gastric malignant melanoma
}

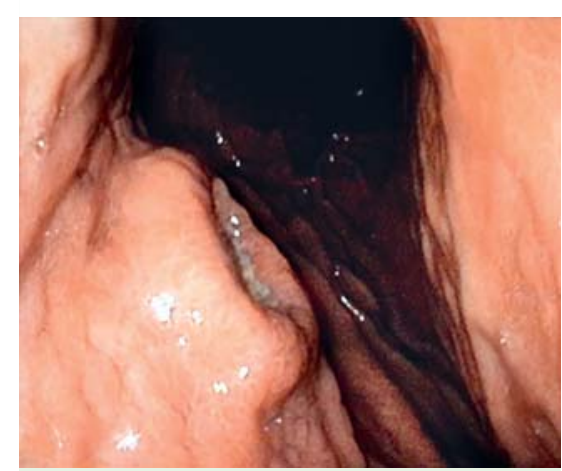

Fig. 1 Endoscopy in a 63-year-old man with epigastric pain and dyspeptic complaints showed a crater-like ulcer in the anterior wall of the gastric body and compression on the posterior wall of the stomach caused by gastrointestinal stromal tumor (GIST).

A 63-year-old man was admitted to our clinic with a 2-month history of epigastric pain and dyspeptic complaints. He had no history of any disease and his vital signs were within normal limits. Physical exam- ination revealed a palpable abdominal mass. Laboratory tests showed unremarkable findings. Upper gastrointestinal endoscopy revealed a crater-like ulcer, approximately $3 \mathrm{~cm}$ in diameter, in the anterior wall of the gastric body, and compression on the posterior wall of the stomach ( Fig. 1). The esophagus and duodenum were unremarkable. Histopathological analysis of an endoscopic biopsy sample from the ulcer revealed malignant melanoma. Abdominal computed tomography showed a large, heterogeneous, cystic solid tumor $15 \mathrm{~cm}$ in diameter, compatible with gastrointestinal stromal tumor (GIST), originating from the posterior wall of the stomach ( $\mathbf{F i g . 2}$ ). Percutaneous biopsy was performed. A diagnosis of GIST was confirmed by histopathological findings. The patient was referred to the surgery and medical oncology departments. GIST is the most common type of mesenchymal tumor and can develop anywhere in the gastrointestinal tract. Half

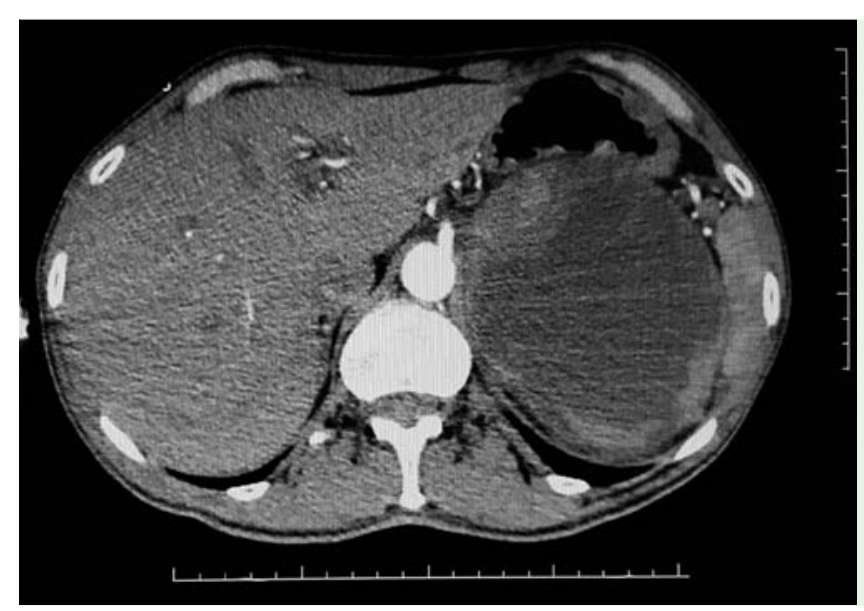

Fig.2 Abdominal computed tomography showed a large, heterogeneous, cystic solid tumor compatible with gastrointestinal stromal tumor (GIST), originating from the posterior wall of the stomach. of all GISTs (50\%) occur in the stomach [1]. The combination of GIST with other gastric tumors is extremely rare. To the best of our knowledge, this is the first reported case of a patient with synchronous gastric malignant melanoma and large gastric GIST.

Endoscopy_UCTN_Code_CCL_1AB_2AD_3AB

Competing interests: None

Barıș Yılmaz ${ }^{1}$ Fuat Ekiz', Akif Altınbas', Bora Aktaş ${ }^{1}$, Suleyman Altıntas ${ }^{2}$

${ }^{1}$ Gastroenterology, Dıskapı Yıldırım Beyazıt Education and Research Hospital, Ankara, Turkey

2 Pathology, Osmaniye State Hospital, Osmaniye, Turkey

\section{Reference}

1 Bennett JJ, Rubino MS. Gastrointestinal stromal tumors of the stomach. Surg Oncol Clin N Am 2012; 21: 21 - 33

\section{Bibliography}

Dol http://dx.doi.org/

10.1055/s-0034-1377981

Endoscopy 2014; 46: E574

(c) Georg Thieme Verlag KG

Stuttgart · New York

ISSN 0013-726X

\section{Corresponding author}

\section{Barış Yılmaz, MD}

Camlikevler mahallesi, 4. Blok No: 6

Toprakkale

Osmaniye

Turkey

Fax: +90-328-8257072

dryilmazb@gmail.com 